NASA Technical Memorandum 107054

NASA-TM-107054

AIAA-95-2401

19960002342

\title{
Long Life Testing of Oxide-Coated Iridium/Rhenium Rockets
}

Brian D. Reed

Lewis Research Center

Cleveland, Ohio

Prepared for the

31st Joint Propulsion Conference and Exhibit cosponsored by AIAA, ASME, SAE, and ASEE San Diego, California, July 10-12, 1995

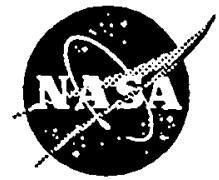

National Aeronautics and Space Administration

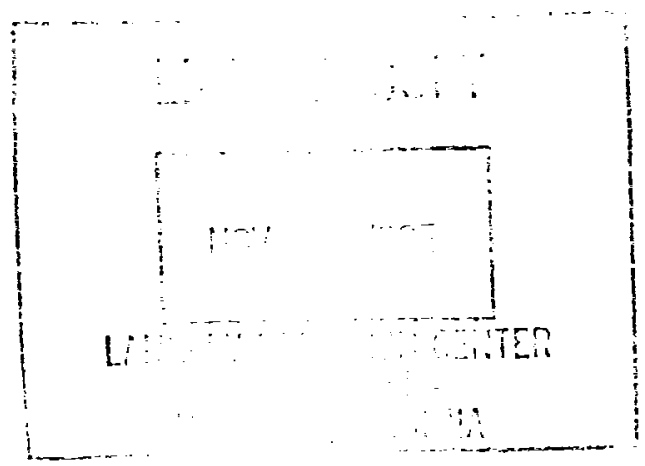




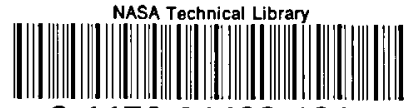

31176014231840

\section{LONG LIFE TESTING OF OXIDE-COATED IRIDIUM/RHENIUM ROCKETS}

\author{
Brian D. Reed \\ NASA-Lewis Research Center \\ Cleveland, Ohio
}

\section{Abstract \\ 22-N class rockets, composed of a rhenium} (Re) substrate, an iridium (Ir) coating, and an additional composite coating consisting of Ir and a ceramic oxide, were tested on gaseous oxygen/gaseous hydrogen (GO2/GH2) propellants. Two rockets were tested, one for nearly 39 hours at a nominal mixture ratio (MR) of 4.6 and chamber pressure $(\mathrm{Pc})$ of $469 \mathrm{kPa}$, and the other for over 13 hours at a nominal MR of 5.8 and $621 \mathrm{kPa}$ Pc. Four additional Ir/Re rockets, with a composite Iroxide coating fabricated using a modified process, were also tested, including one for 1.3 hours at a nominal $\mathrm{MR}$ of 16.7 and $\mathrm{Pc}$ of $503 \mathrm{kPa}$. The long lifetimes demonstrated on low MR GO2/GH2 suggest greatly extended chamber lifetimes (tens of hours) in the relatively low oxidizing combustion environments of Earth storable propellants. The oxide coatings could also serve as a protective coating in the near injector region, where a still-mixing flowfield may cause degradation of the Ir layer. Operation at MR close to 17 suggests that oxide-coated Ir/Re rockets could be used in severely oxidizing combustion environments, such as high MR GO2/GH2, oxygen/hydrocarbon, and liquid gun propellants.

\section{Introduction}

The most common material system currently used for radiation-cooled rockets is a niobium alloy subsurate (C103) with a fused silica coating (R512E) for oxidation protection. Significant amounts of fuel film cooling are required to keep this material system below its maximum operating temperature of $1370^{\circ} \mathrm{C}$, adversely affecting engine performance. A new class of high-temperature, oxidation-resistant materials is under development for radiation-cooled rockets. These materials have the thermal margin to allow rocket operation up to $2200^{\circ} \mathrm{C}$. The large thermal margin allows the reduction or elimination of fuel film cooling, while still exceeding the life of silicide-coated niobium (R512E/C103) rockets. A material system composed of a rhenium (Re) substrate (for high temperature \& strength) and an iridium (Ir) coating (for oxidation protection) has proven to provide high-temperature $\left(2200^{\circ} \mathrm{C}\right)$, long-life (hours) operation for radiationcooled rockets operating on Earth storable propellants (ref. 1). The use of ceramic oxides as an additional coating for iridium/rhenium ( $I r / R e$ ) rocket chambers is being evaluated. The addition of these oxide coatings could further increase the lifetimes of $\mathrm{I} / \mathrm{Re}$ rockets and allow operation in more oxidizing combustion environments than Earth storable propellants. The oxide coatings that are being evaluated for Ir/Re rockets include hafnia $\left(\mathrm{HfO}_{2}\right)$, zirconia $\left(\mathrm{ZrO}_{2}\right)$, and a composite coating composed of Ir and an oxide.

The primary life limiting mechanism for $\mathrm{Ir} / \mathrm{Re}$ chambers is the diffusion of $\mathrm{Re}$ into the Ir layer. As the concentration of $R e$ increases at the Ir surface, the Ir oxidation resistance continually degrades. When a critical $R e$ concentration at the inner surface is reached, the Ir oxidation rate increases significantly, leading to the rapid removal of Ir and oxidation of the underlying $\operatorname{Re}$ (ref. 2). Re diffusion into Ir and oxidation of Ir are both temperature-driven processes. The low thermal conductivity oxide layer acts as a thermal barrier, significantly lowering the temperature at the Ir surface, where oxidation takes place, and at the Re-Ir interface, where Re diffusion occurs. The oxide layer also acts as a diffusion barrier, slowing the ingress of oxidizers to the Ir surface and the egress of Ir oxidation products from the Ir surface. Furthermore, an oxide layer would serve as a protector against Ir degradation experienced in some testing of Ir/Re rockets (ref. 3 ). The presence of an oxide coating would prevent the Ir layer from being exposed to a still-mixing, still-combusting flowfield, which is the suspected cause of the Ir degradation. The synergistic effects of oxide coatings could result in significantly longer life for Ir/Re rockets operating on Earth storable propellants and enable operation in aggressively oxidizing combustion environments that would not be possible for Ir/Re alone.

A previous technology program (ref. 4) evaluated seven oxide-coated Ir/Re rockets through testing on gaseous oxygen/gaseous hydrogen (GO2/GH2) propellants. Six of the 22-N thrust class rockets were coated with monolithic layers of either $\mathrm{HFO}_{2}$ or $\mathrm{ZrO}_{2}$ and tested from mixture ratio (MR) 4 to 11. A seventh Ir/Re rocket had a composite coating consisting of Ir and an oxide. This chamber was tested from MR 4 to 16 , including over 29 minutes at MR 
16. The Ir-oxide composite coating proved to be the most promising and was selected for further evaluation.

This paper will summarize the testing of six 22-N Ir/Re rockets coated with Ir-oxide composites. Estimates of the wall temperature gradient and the composition of the combustion environment will be included with test results. The posttest condition of the rocket chambers and conclusions about the life limiting mechanisms of the oxide coatings on Ir/Re will be discussed. This paper will also review potential applications for oxide-coated Ir/Re rockets.

\section{Review of Previous Oxide-Coated Ir/Re Program (ref. 4)}

The development of oxide coatings for Ir $/ R e$ rocket chambers was the subject of Small Business Innovative Research (SBIR) contract with Ultramet (refs. 5 and 6). After review and screening of potential oxide coatings, $\mathrm{ZrO}_{2}$ and $\mathrm{HfO}_{2}$ were selected as coatings for Ir/Re chambers. These refractory oxides have higher melting points than Ir but are permeable to oxygen and, therefore, cannot be used as the primary oxidation barrier. A key technology issue associated with oxide coatings was their ability to withstand the thermal shock of combustion and to adhere after thermal cycling. Thermomechanical, thermochemical, and mass transport modeling of the oxide/Ir/Re material system was performed to guide fabrication. The modeling and analyses of the oxide coating fabrication process are discussed in reference 7.

Seven 22-N class rocket chambers were fabricated in this SBIR. Five of the chambers had monolithic coatings of either $\mathrm{ZrO}_{2}$ or $\mathrm{HfO}_{2}$, with thicknesses ranging from 254 to $864 \mu \mathrm{m}$. Another chamber had a monolithic coating of $\mathrm{ZrO}_{2}$, but only with a thickness of $25 \mu \mathrm{m}$. This coating was also infiltrated with sol gel $\mathrm{HfO}_{2}$. The seventh chamber had a composite coating composed of Ir and an oxide. The identity of the oxide is proprietary to Ultramet. The thickness of this Ir-oxide composite coating was 76 $\mu \mathrm{m}$.

The seven chambers were tested on $\mathrm{GO} 2 / \mathrm{GH} 2$ propellants in order to assess the ability of the oxide coatings to withstand the thermal shock of combustion initiation, adhere under repeated themal cycling, and operate in aggressively oxidizing environments. Testing was conducted at chamber pressures (Pc) from
572 to $627 \mathrm{kPa}$. All of the coatings survived the thermal shock of combustion and demonstrated operation at MR from 4 to 11. The chambers were tested in 18 to 27 firings each, for total test durations ranging from 25 to 32 minutes. The chamber with the Ir-oxide composite coating was tested for an additional 30 firings and over 29 minutes at MR 16. Reference 4 provides a more detailed discussion of this test program.

The five chambers with thick (greater than 254 $\mu \mathrm{m})$, monolithic coatings were susceptible to "mudflat" cracking, with visible cracks observed down the interior of the chambers after 6 firings. The cracks apparently resealed under compression of the oxide layer during firing, only to reopen upon chamber cooldown. Chipping and spalling of the coating occurred after repeated thermal cycling, particularly at a stress concentrator located at the head end of the chambers.

The two chambers with thin (less than $76 \mu \mathrm{m}$ ) coatings (one monolithic, the other Ir-oxide composite) did not experience the visible cracking and chipping seen in the thick coatings. Posttest inspection did reveal microcracking that had not been apparent from visual inspections during testing. Burn-throughs through the wall occurred in both of these chambers, at the throat. The thin oxide layers allowed more rapid diffusion of oxidizers to the underlying Ir. Operation in combustion environments above stoichiometric $(\mathrm{MR}=$ 8) accelerated this effect, leading to an aggressive oxidative attack of the Ir and Re layers and bum-through at the throat.

Of the seven chambers that were tested in this program, the one with the Ir-oxide composite coating (labeled S/N 6063-1-10) was thought to be the most resilient. Despite the wall burn-through the chamber had experienced, there was an absence of mudflat cracking in the coating and operation in the highly oxidizing environment of MR $16 \mathrm{GO} 2 / \mathrm{GH} 2$ had been achieved. The Ir-oxide composite coating was selected for further development.

\section{Current Oxide-Coated Ir/Re Chamber Program}

Six chambers, all with Ir-oxide composite coatings, were tested in this program. The chamber structures are summarized in Table I. One chamber, S/N 6082-1-3, had an identical structure to the Ir-oxide composite coated chamber (S/N 6063-1-10) tested in the previous program (ref. 4). A second chamber, $S \mathbb{N}$ 
6082-1-4, also had an Ir-oxide composite coating, but with a different structure. The remaining four chambers (S/N 6909-1-1, -1-2, -1-4, and -1-5) were fabricated using a modified approach to the Ultramet proprietary process (ref. 8).

The two chambers from the S/N 6082 series were tested to assess the lifetime of the Ir-oxide composite coating. The $S / N$ 6082-1-3 chamber was tested in a combustion environment with an oxygen pressure comparable to an Earth storable propellant environment. The $S / N$ 6082-1-4 chamber was tested in an environment with an oxygen pressure that was an order of magnitude higher than in Earth storable propellants. The four chambers of the S/N 6909 series were tested to assess the modified fabrication process. These chamber were tested for the purpose of subjecting the coatings to repeated thermal cycles in an oxidizing environment.

\section{Rocket Chamber Geometry \\ All of the rocket chambers tested had the same}

\section{Test Apparatus} geometry. The chambers had a long, skinny barrel section to promote mixing and combustion. The barrel had an inner diameter of $0.894 \mathrm{~cm}$ and a length of 3.5 $\mathrm{cm}$. The contraction ratio was $4.3: 1$ with a smooth, gradual converging contour to the throat, which had an inner diameter of $0.432 \mathrm{~cm}$. The nozzle was an $8: 1$ area ratio, $15^{\circ}$ half-angle cone. A $37^{\circ}$ angle cone at the head end was used for attachment to the injector assembly. The rocket was sized for mass flowrates corresponding to a $22 \mathrm{~N}$ thrust level. This chamber geometry had been successfully fabricated by Ultramet and tested by Gencorp Aerojet and NASA in previous rocket chamber material screening tests (refs. 4 and 9).

\section{Injector Assembly}

The chambers were attached to an assembly consisting of a water-cooled section and injector. A sketch of the injector assembly is shown in figure 1 . The injector body had a center annulus for a spark plug. The oxygen was injected radially around the spark plug tip to flow down the center annulus. A small amount of hydrogen was injected radially downstream of the spark plug to ignite the energized oxygen. Six impinging elements injected hydrogen into the center annulus flow, while six elements injected hydrogen axially into the chamber for fuel film cooling. The $5.08 \mathrm{~cm}$-long, water-cooled section had a trip ring 2.54 $\mathrm{cm}$ downstream of the injector face to promote mixing of the fuel film into the core flow and elimination of streaking. The water-cooled section also protected the front end from thermal soakback from the chamber. The water flowrate through the section was typically 8 to $15 \mathrm{lpm}$. The conical head end of the chamber was clamped to a cone on the face of the water-cooled section by a split ring and sealed using 0.0127 - and 0.0254-cm sheets of Grafoil, a flexible graphite gasket material.

\section{Purge Assembly}

The exterior rhenium surface was purged with an inert gas to prevent the oxidation of the $\mathrm{Re}$ and an "outside-in" failure of the chamber. A 24-element ring was used for injection of the purge gas around the chamber exterior. The purge was contained in a 5.20$\mathrm{cm}$ diameter fused silica tube, with a $2.54-\mathrm{cm}$ inner diameter, stainless steel end cap. Springs were used to hold the tube to the purge ring, while allowing some movement due to thermal growth. The purge gas was either helium ( $71 \mathrm{lpm})$ or argon $(-47 \mathrm{lpm})$, based on availability of the gas. An oxygen absorbing purifier was used in the purge line to insure that the purge gas had less than 0.1 parts per million of oxygen. The exterior purge was initiated before the first test in a series and maintained until after a series of tests was completed and ambient pressure had been re-established in the test tank (by which time the chamber had cooled to ambient temperature).

\section{Instrumentation}

A pressure tap in the injector face was used to measure the static $\mathrm{Pc}$. This static $\mathrm{Pc}$ measurement was corrected for momentum pressure loss across the combustion zone and converted to total pressure. Hydrogen and oxygen mass flowrates were calculated using the inlet pressures, inlet temperatures, and discharge coefficients of critical flow venturis, with corrections for real gas effects (ref. 10). The measurement uncertainties of the mass flowrates and MR were related from measured parameters using Taylor's series expansion as per the JANNAF recommended procedure (ref. 11). The measurement uncertainties were less than $+/-1$ percent for all of the mass flowrates, MR's, and characteristic exhaust velocities $\left(C^{*}\right)$.

Outer wall temperature of the chamber was measured using an Ircon Modline Plus two-color pyrometer. The two-color pyrometer viewed two 
wavelength bands and used the ratio of the two signals to calculate temperature. As such, the absolute emissivity of the target was not required but rather the change in emissivity over the two wavelength bands. For the black, dendritic rhenium surfaces in this testing, the emissivity was assumed to be constant over the two wavelength bands. The two-color pyrometer was aimed at the beginning of the converging section on the chamber (the position of highest temperature) and had an approximately $1.0-\mathrm{cm}$ diameter spot size. The temperature range of the two-color pyrometer was from $982^{\circ} \mathrm{C}$ to $3315^{\circ} \mathrm{C}$ and its measurement error was +1 $27^{\circ} \mathrm{C}$.

\section{Test Facility}

Testing of the chambers was conducted at a NASA Lewis Research Center propulsion test facility, Rocket Lab 11. The facility was designed for research of low thrust rockets operating on $\mathrm{GO} 2 / \mathrm{GH} 2$ propellants, at thrust levels below $220 \mathrm{~N}$, in long duration steady state or cyclic tests. The rocket was mounted in a $0.91-\mathrm{m}$, cylindrical test tank with viewports for optical access. A two-stage air ejector system maintained a $1.4 \mathrm{kPa}$ pressure in the tank, equivalent to an altitude of $36.6 \mathrm{~km}$. The rocket was mounted horizontally and fired into a water-cooled diffuser. All data were recorded on a PC-based data acquisition system and performance parameters were calculated in real time. A more detailed description of the test facility is available in reference 12 .

\section{Test Conditions}

\section{Test Results}

Table II summarizes the testing conducted on the chambers in this program. Most of the testing for the $S / N 6082$ chambers were conducted in 10-, 30-, and 60 -min test durations with the purpose of accumulating life on the chambers. The 6082-1-3 chamber was tested in 94 firings for 140,099 sec ( $38.9 \mathrm{hrs}$ ) total duration. The majority of the testing (91 firings, $139,867 \mathrm{sec}$ ) was conducted at a nominal MR of 4.6 and a Pc of 462 $\mathrm{kPa}$. Testing was stopped when the coating began flaking off the chamber in the throat region. The 6082$1-4$ chamber was tested for $47,773 \mathrm{sec}(13.3 \mathrm{hrs})$ in 50 firings, at a nominal MR of 5.8 and $621 \mathrm{kPa}$ Pc. The chamber suffered a burn-through in the throat region.

The S/N 6909 series chambers were tested with the purpose of accumulating thermal cycles on the coatings. Testing was done primarily in 1-min and 5- min durations. As the 6909-1-1 and -1-2 chambers accumulated over 20 thermal cycles, 15 - and 30-min duration tests were conducted to accumulate lifetime on the chambers.

The 6909-1-4 and-1-5 chambers were tested at a nominal MR of 6.3. The $-1-4$ chamber accumulated 13 firings and 1,521 $\mathrm{sec}(25.4 \mathrm{~min}$ ) at Pc's ranging from 558 to $676 \mathrm{kPa}$. The $-1-5$ chamber was tested for a total of 21 firings and 5,858 sec (1.63 hrs) at Pc's from 579 to $717 \mathrm{kPa}$. The Pc varied for these chambers, due to erosion in the throat region. For both the $-1-4$ and 1-5 chambers, wall burn-throughs occurred at the throat.

Testing of the 6909-1-2 chamber was conducted initially at MR 6, but at a lower Pc than the 1-4 and -1-5 chambers, in order to lower the combustion temperature. When outer wall temperature did not decrease, the MR was lowered to 4, which did result in lower wall temperatures. The 6909-1-2 chamber was tested for 42 firings and 34,186 sec (9.50 hrs), primarily at a nominal MR of 4.1 and a Pc of $517 \mathrm{kPa}$. This total includes 8 firings and $447 \mathrm{sec}$ at a MR of 6.1 and $\mathrm{Pc}$ of $372 \mathrm{kPa}$. No signs of any significant degradation of its coating were found at the end of testing.

The 6909-1-1 chamber was tested in 36 firings for 4,624 sec (1.28 hrs) total duration, at a nominal MR of 16.7 and $\mathrm{Pc}$ of $600 \mathrm{kPa}$. This testing was done to assess the coating lifetime in a severely oxidizing combustion environment. Testing ended in a burnthrough at the throat.

$C^{*}$ efficiency, a measure of combustion efficiency, was calculated using the Chemical Equilibrium Compositions (CEC) code (ref. 13). The CEC code (which assumes complete combustion and equilibrium reactions) was used to calculate the maximum possible $C^{*}$. The $C^{*}$ efficiencies for this testing ranged from 88 to 95 percent.

In order to get an estimate of the combustion environment, the CEC code was also used to calculate species partial pressures. Table III lists the partial pressures of oxygen and other species that are possibly damaging to Ir, for the test conditions in this program. For comparison, species partial pressures for typical Earth storable, oxygen/ethanol, and liquid gun propellant combustion environments are also listed. 


\section{Wall Temperature Gradient}

The inner wall temperature of the chambers was estimated from the outer wall temperature measurement and using an energy balance between the one-dimensional, steady-state heat conduction through the chamber wall and the radiation emitted from the chamber outer wall. The temperatures at the oxide/Ir and $I r / R e$ interfaces were also found using this energy balance. The methodology is explained in detail in reference 4.

The outer wall temperatures ranged from 1830 to $1925^{\circ} \mathrm{C}$ and 2065 to $2150^{\circ} \mathrm{C}$ for the S/N $6082-1-3$ and 6082-1-4 chambers, respectively. The typical temperature gradients $(\Delta \mathrm{T})$ through the wall for both chambers are given in figure 2 . The Ir-oxide composite coating provided a substantial temperaure gradient in both chambers.

The 6909-1-4 and -1-5 chambers were tested at outer wall temperatures from 2120 to $2250^{\circ} \mathrm{C}$. The 6909-1-2 outer wall temperature was $2265^{\circ} \mathrm{C}$ for its MR 6 tests and ranging from 1910 to $2000^{\circ} \mathrm{C}$ for the MR 4.1 tests. The outer wall temperatures for the 6909-1-1 chamber were measured to be 1870 to 1925 'C. The typical $\Delta T$ 's for the $S / N 6909$ chambers are shown in figure 3.

As with the $S / N 6082$ chambers, there was a substantial temperature drop through the Ir-oxide composite layer. However, the thicker $\mathrm{Re}$ and Ir-oxide layers in the 6909-1-4 and -1-5 chambers provided for a larger overall temperature drop through the wall. When these chambers were tested at MR 6 (resulting in outer wall temperatures above $2200^{\circ} \mathrm{C}$ ), the inner wall temperature went above the melting point of $\operatorname{Ir}(2430$ $\left.{ }^{\circ} \mathrm{C}\right)$. As a result, the Ir in the Ir-oxide composite coating melted in these chambers. Since the 6909-1-2 chamber had a thinner wall than the $-1-4$ and $-1-5$ chambers, the Ir melting temperature was avoided for the 8 firings it ran at MR 6 and above $2200^{\circ} \mathrm{C}$.

Postlest Examination

The 6082-1-3 chamber was tested for 94 firings and nearly 39 hours, when flaking of the inner layer was observed in the throat region. Although the chamber had not suffered a burn-through at this point testing was stopped. Figure 4 shows the sectioned 6082-1-3 chamber. The S/N 6063-1-10 chamber from the previous program had the identical structure. Both chambers exhibited a pattern of microcracking down the length of the chamber, although this had not been evident from visual inspections during testing.

The 6082-1-3 chamber failed in a different manner from the 6063-1-10 chamber, however. Testing of the 6082-1-3 chamber was stopped when it experienced spalling of its coating. Neither the Re exterior nor the Ir layer underlying the spalled material showed signs of the aggressive oxidative attack seen in the 1-10 chamber. The 6082-1-3 chamber operated in a less severe oxygen environment $(0.64 \mathrm{kPa}$ oxygen partial pressure) than the 1-10 chamber, but was subjected to nearly double the number of firings ( 94 versus. 52 for the 1-10 chamber). The 6082-1-3 chamber apparently failed by repeated compression of the coating during heating and subsequent cracking upon cooling, leading to the spalling of the coating. This is evident in figure 5 , which is a micrograph (5 times magnification) of the throat region of the 6082-1-3 chamber. This type of spalling was seen in the previous program for the five chambers with thick, monolithic coatings of either $\mathrm{ZrO}_{2}$ or $\mathrm{HfO}_{2}$. Because the coating was relatively thin for the 6082-1-3 chamber, the thermal stress failure mechanism did not become evident until after many firings.

The 6082-1-4 chamber experienced a burnthrough in the throat region after 13.3 hours and 50 firings. Visual inspection of the chamber during testing had revealed no obvious degradation of the coating, although posttest examination showed microcracking in the coating. The $6082-1-4$ chamber was subjected to nearly eight times the oxygen partial pressure of the $6082-1-3$ chamber and had about half the lifetime. This would seem to indicate that the 6082-1-4 chamber was subjected oxidative attack of the underlying $\operatorname{Re}$ and Ir layers leading to the burn-through. This was the same manner in which the Ir-oxide composite coated chamber from the previous program (S/N 6063-1-10) failed. In that case the chamber was also subjected to a severely oxidizing environment.

The 6909-1-4 and -1-5 chambers both suffered wall burn-throughs at the throat. With these chambers, the inner wall temperatures were high enough to melt the Ir in the Ir-oxide composite coating. Visual inspections of the $-1-4$ and $-1-5$ chambers during testing showed melted Ir deposited along the inner wall. The melting of Ir in the Ir-oxide composite was probably responsible for the breakdown of the coating and ultimately, burn-through in both chambers. 
The 6909-1-1 chamber failed in the same manner as the 6063-1-10 and 6082-1-4 chambers, that is, through oxidative attack of the underlying Ir and $\operatorname{Re}$ layers leading to a burn-through at the throat region. As with those chambers, the failure was caused by operating in a severely oxidizing environment, in this case, MR 16.7 (184 kPa oxygen partial pressure).

The 6909-1-2 chamber successfully ran $9.5 \mathrm{hrs}$ without failure. The inner wall of the chamber showed no evidence of melting or degradation of the Ir-oxide composite coating.

\section{Analysis}

The test time accumulated for the chambers tested in this program is plotted as a function of oxygen environment in figure 6 . From the testing in this and the previous program, general conclusions about the behavior of oxide coatings on Ir/Re chambers can be drawn.

Thick oxide coatings (over $254 \mu \mathrm{m}$ ) appear to be susceptible to extensive cracking after a few thermal cycles ( 6 at maximum). This cracking is due to repeated compression of the oxide layer during firing and tension during cooldown. The thermal-induced stresses have led to the spalling of the coating after a total of 20 to 25 thermal cycles. The large wall temperature gradients experienced with the thick coatings also indicated a large diffusion barrier. The spalling of the coating, then, would seem to occur before the underlying Ir and $R e$ layers can be subjected to serious oxidative attack. A caveat to the conclusions drawn here is that all of the thick-coated chambers were with monolithic layers of either $\mathrm{ZrO}_{2}$ or $\mathrm{HfO}_{2}$. There has not been testing conducted with a Ir-oxide composite coatings greater than $178 \mu \mathrm{m}$ in thickness.

Thin oxide coatings (under $178 \mu \mathrm{m}$ ) operating in moderately oxidizing environments appear to be able to complete several thermal cycles (the 6082-1-3 chamber completed over 90 cycles in $0.64 \mathrm{kPa}$ oxygen) before thermal stresses induce spalling. The cracking in the thin coatings will be less severe than that experienced for thicker coatings. As with thicker coatings, spalling will probably take place before oxidative attack of the Ir and Re layers with subsequent burn-through.
For thin oxide coatings operating in severe oxygen environments, oxidative attack of the underlying Ir and Re layers (by diffusion of oxygen through the oxide layer) will fail the chamber before spalling of the coating can occur. The number of thermal cycles that can be completed before failure appears to be a strong function of the oxygen partial pressure the coating is exposed to. 50 thermal cycles were completed on the 6082-1-4 chamber in a $5.03 \mathrm{kPa}$ oxygen environment before failure. The 6909-1-1 chamber completed 36 thermal cycles in $184 \mathrm{kPa}$ oxygen.

Potential Applications for Oxide-Coated Ir/Re Rockets Lifetimes under 10 hours have been demonstrated on 440-N class, Ir $/ \mathrm{Re}$ engines operating with Earth storable propellants, such as nitrogen tetroxide/monomethylhydrazine (MMH/NTO) and NTO/hydrazine (N2H4) (refs. 1, 9, and 14). The 60821-4 chamber was subjected to an oxidizing environment nearly an order of magnitude higher than in Earth storable propellant combustion environments (table II). Over 13 hours in $5.03 \mathrm{kPa}$ oxygen (S/N 6082-1-4) and 39 hours in $0.64 \mathrm{kPa}$ oxygen ( $/ \mathrm{N} 6082-1-3$ ) suggest greatly extended lifetimes in the Earth storable environments, which are under $0.71 \mathrm{kPa}$ oxygen partial pressure. Tens of hours of operation are projected for Earth storable propellants using oxide-coated Ir/Re chambers.

As mentioned earlier, local degradation of Ir has been experienced in the testing of some Ir $/ \mathrm{Re}$ rockets (ref. 3). No problems with Ir degradation have been experienced with rockets using a regenerativelycooled head end or platinum-rhodium ( $\mathrm{Pt}-\mathrm{Rh}$ ) alloy sleeve in the near-injector region of the chamber (refs. 1,9 , and 14). In these cases, the Ir coating was only exposed to a well-mixed flow. Circumstantial evidence, then, would indicate that the degradation was the result of Ir exposure to a still-mixing, still-combusting flowfield (ref. 15). Specifically, the Ir could be reacting with free oxygen or a combustion radical (possibly hydroxyl). Oxide coatings could serve the same function as a cooled-head end or Pt-Rh sleeve, protecting the Ir layer from exposure to the flowfield in the near-injector region. A coating would be less intrusive than a cooled-section or sleeve. Furthermore the oxide coatings (whether $\mathrm{ZrO}_{2}, \mathrm{HrO}_{2}$ or an Ir-oxide composite) have a higher melting point than Ir and could therefore be used down the entire length of the chamber. 
Advanced monopropellants developed in liquid gun applications (ref. 16) are under consideration for small rockets. The combustion products of the LP $\mathrm{XM}-46$ (the most developed liquid gun propellant) includes high concentrations of oxygen and water vapor. Because there is no opportunity for film cooling in a monopropellant engine, protection of the substrate material will be completely dependent on the oxidationresistant coating.

The next generation of manned, reusable launch vehicles may use nontoxic propellants for its Reaction Control System (RCS). The use of nontoxic $\mathrm{RCS}$ is one of the ways to reduce the processing costs and time in reusable launch vehicles (ref. 17). A GO2/GH2 RCS, operating at MR 16, was recommended in a study comparing different oxygen/hydrogen RCS concepts (ref. 18). A RCS utilizing oxygen/ethanol was recommended by a study investigating a nontoxic RCS for the Space Shuttle (ref. 19). Other hydrocarbon fuels with oxygen as well as liquid gun propellants are under consideration for advanced RCS. Most of the nontoxic RCS concepts under study utilize propellant combinations that generate more severely oxidizing environments than Earth storable propellants. The demonstration of 1.28 hrs of time in $184 \mathrm{kPa}$ oxygen (S/N 6909-1-1 chamber) indicates that long-life operation on the highly oxidizing, nontoxic propellants may be possible with oxide-coated Ir/Re rockets.

\section{Concluding Remarks}

Ir/Re rockets with oxide coatings have demonstrated significant chamber lifetimes in oxidizing combustion environments. The oxide coatings tested in this program were composite coatings composed of Ir and an oxide. Nearly 39 hours of testing was demonstrated on an oxide-coated Ir/Re chamber with GO2/GH2 propellants at MR 4.6, which is an oxygen environment $(0.64 \mathrm{kPa})$ comparable to Earth storable propellant combustion environments. Another chamber demonstrated 9.5 hours at MR $4.1(0.23 \mathrm{kPa}$ oxygen pressure) without any signs of degradation of the coating. Over 13 hours of time was accumulated on an oxide-coated Ir/Re chamber operating in an oxygen environment (MR 5.8,5.0 kPa) an order of magnitude higher than Earth storable propellant combustion environments. Two chambers operating at MR 6.3 (8.9 $\mathrm{kPa}$ oxygen pressure) experienced inner wall temperatures high enough to melt the Ir in the Ir-oxide composite coating. One oxide-coated Ir/Re chamber demonstrated 1.28 hours in a severely oxidizing environment (MR 16.7, $184 \mathrm{kPa}$ oxygen pressure).

The testing conducted in this program suggest oxide-coated Ir/Re rockets offer significantly extended chamber lifetimes (tens of hours) for Earth storable propellants. Oxide coatings may also serve as a protector against degradation of Ir in the near injector region of Ir/Re chambers. For applications that require operation in more oxidizing environments (advanced monopropellants, advanced RCS), oxide coatings on Ir/Re may be the only material option for hours of chamber lifetime.

\section{References}

1. Schneider, S.J.: Low Thrust Chemical Rocket Technology, NASA TM-105927, IAF Paper 92-0669, September 1992.

2. Jassowski, D.M.: Advanced Small Rocket Chambers, Basic Program and Option II, Final Report, Contract NAS3-25646, CR-195349, September 1993.

3. Wood, R.: Experiences with High Temperature Materials for Small Thrusters, AIAA Paper 93-1963, June 1993.

4. Reed, B.D.: Evaluation of Oxide-Coated IridiumRhenium Chambers, NASA TM-106442, 1993 JANNAF Propulsion Meeting, November 1993.

5. Tuffias, R.H., et. al.: Enhanced Oxidation Protection for Iridium-Lined Rhenium Thrust Chambers, Final Report, Contract NAS3-25468, June 1990.

6. Tuffias, R.H., et. al.: Protective Oxide Coatings for Iridium/Rhenium Chambers, Final Report, Contract NAS3-26253, May 1995.

7. Tuffias, R.H., et. al.: Design, Analysis, and Fabrication of Oxide-Coated Iridium/Rhenium Combustion Chambers, 1993 JANNAF Propulsion Meeting, November 1993.

8. Tuffias, R.H.: Iridium Life Enhancement for Advanced Chemical Propulsion, Contract NAS9-19103 managed by NASA Johnson Space Center, Final Report 
to be published.

9. Schoenman, L.: $4000^{\circ} \mathrm{F}$ for Low Thrust Rocket Engines, AIAA Paper 93-2406, June 1993.

10. Fluid Meters: Their Theory and Application, American Society of Mechanical Engineers, 1971.

11. Handbook For Estimating the Uncertainty in Measurements Made With Liquid Propellant Rocket Engine Systems, Chemical Propulsion Information Agency Document Number 180, April 1969.

12. Arrington, L.A. and Schneider, SJ.: Low Thrust Rocket Test Facility, AIAA Paper 90-2503, NASA TM-103206, July 1990.

13. Gordon, S. and McBride, B.: Computer Program for Calculation of Complex Chemical Equilibrium Composition, Rocket Performance, Incident and Reflected Shocks, and Chapman-Joguet Detonations, NASA SP-273, March 1976.

14. Jassowski, D.M. and Schoenman, L.: Advanced Small Rocket Chambers, Option 3, Final Report, Contract NAS3-25646, CR-195435, November 1994.

15. Reed, B.D., Biaglow, J., and Schneider, S.J.: Advanced Materials for Radiation-Cooled Rockets, Proceedings of the 5th Annual Symposium of the NASA Propulsion Engineering Research Center, Pennsylvania State University, September 8-9, 1993 , pp. 115-118.

16. Liquid Propellant XM46 Handbook, Jet Propulsion Laboratory, prepared for Armament Research, Development and Engineering Center, U.S. Department of the Army, July 1994.

17. Operationally Efficient Propulsion System Study, Final Report, Contract NAS10-11568, May 1989.

18. Gerhardt, D.L.: Integrated Hydrogen/Oxygen Technology Applied to Auxiliary Propulsion Systems, Final Report, Contract NAS3-25643, NASA CR185289, September 1990.

19. Orton, G.F.: LOX/Hydrocarbon Auxiliary Propulsion System Study, Final Report, Contract NAS9-16305, July 1982. 
Table I: Chamber Structures

\begin{tabular}{lccc} 
Chamber & Coating Thickness $(\mu \mathrm{m})$ & Ir Thickness $(\mu \mathrm{m})$ & $\frac{\text { Re Thickness }(\mu \mathrm{m})}{6082-1-3}$ \\
\cline { 2 - 3 } & 89 & 46 & 1707 \\
$6082-1-4$ & 71 & 46 & 2207 \\
$6909-1-1$ & 107 & 46 & 1067 \\
$6909-1-2$ & 89 & 38 & 1702 \\
$6909-1-4$ & 178 & 38 & 2032 \\
$6909-1-5$ & 163 & 41 & 2489
\end{tabular}

Table II: Test Summary

\begin{tabular}{|c|c|c|c|c|}
\hline Chamber & Firings & Time (sec) & $\underline{\mathrm{MR}}$ & $\underline{\operatorname{Pc}(k P a)}$ \\
\hline S/N $6082-1-3 \dagger$ & 94 & 140,099 & 4.6 & 441 to 490 \\
\hline S/N 6082-1-4 & 50 & 47,773 & 5.8 & 593 to 648 \\
\hline S/N 6909-1-1 & 36 & 4,624 & 16.7 & 503 \\
\hline S/N 6909-1-2‡ & 42 & 34,1861 & 4.1 & 496 to 534 \\
\hline S/N 6909-1-4 & 13 & 1,521 & 6.3 & 600 to 676 \\
\hline S/N 6909-1-5 & 21 & 5,858 & 6.3 & 579 to 717 \\
\hline
\end{tabular}

$\dagger$ Includes 2 firings for $65 \mathrm{sec}$ at $\mathrm{MR}=7, \mathrm{Pc}$ 's $=579$ and $600 \mathrm{kPa}$ and 1 firing for $167 \mathrm{sec}$ at $\mathrm{MR}=6, \mathrm{Pc}=627 \mathrm{kPa}$ $\ddagger$ Includes 8 firings and $447 \mathrm{sec}$ at $\mathrm{MR}=6.1, \mathrm{Pc}=372 \mathrm{kPa}$

TNot tested to failure 
Table III: Species Partial Pressures for Various Combustion Environments

\begin{tabular}{|c|c|c|c|c|c|}
\hline \multirow[b]{2}{*}{ Combustion Environment } & \multicolumn{4}{|c|}{ Species Partial Pressure (kPa) } & \multirow[b]{2}{*}{$\underline{\mathrm{NO}}$} \\
\hline & $\mathrm{O}_{2}$ & $\underline{\mathrm{OH}}$ & $\underline{Q}$ & $\underline{\mathrm{H}}_{2} \mathrm{O}$ & \\
\hline $\mathrm{GO} 2 / \mathrm{GH} 2$ & 0.23 & 8.60 & 0.53 & 248 & - \\
\hline \multicolumn{6}{|l|}{$\begin{array}{l}M R=4.1, P c=515 \mathrm{kPa} \\
S / N \text { 6909-1-2 Chamber Test }\end{array}$} \\
\hline $\mathrm{GO} 2 / \mathrm{GH} 2$ & 0.64 & 13.3 & 1.22 & 239 & -- \\
\hline \multirow{2}{*}{\multicolumn{6}{|c|}{$\begin{array}{l}M R=4.6, P c=462 \mathrm{kPa} \\
S / N \text { 6082-1-3 Chamber Test }\end{array}$}} \\
\hline & & & & & \\
\hline $\mathrm{GO} 2 / \mathrm{GH} 2$ & 5.03 & 38.5 & 5.88 & 361 & - \\
\hline \multirow{2}{*}{\multicolumn{6}{|c|}{$\begin{array}{l}\mathrm{MR}=5.8, \mathrm{Pc}=621 \mathrm{kPa} \\
\mathrm{S} / \mathrm{N} 6082-1-4 \text { Chamber Test }\end{array}$}} \\
\hline & & & & & \\
\hline $\mathrm{GO} 2 / \mathrm{GH} 2$ & 8.92 & 49.2 & 8.69 & 387 & - \\
\hline \multirow{2}{*}{\multicolumn{6}{|c|}{$\begin{array}{l}M R=6.3, P c=648 \mathrm{kPa} \\
S / N 6909-1-4 \text { and }-1-5 \text { Chamber Tests }\end{array}$}} \\
\hline & & & & & \\
\hline $\mathrm{GO} 2 / \mathrm{GH} 2$ & 184 & 60.0 & 19.1 & 317 & - \\
\hline \multicolumn{6}{|l|}{$\mathrm{MR}=16.7, \mathrm{Pc}=600 \mathrm{kPa}$} \\
\hline S/N 6909-1-1 Chamber Test & . & & & & \\
\hline NTO/N2H4 & 0.18 & 4.90 & 0.19 & 278 & 0.59 \\
\hline \multicolumn{6}{|l|}{$\mathrm{MR}=1.0, \mathrm{Pc}=690 \mathrm{kPa}$} \\
\hline NTO/MMH & 0.71 & 10.0 & 0.84 & 227 & 1.40 \\
\hline \multicolumn{6}{|l|}{$\mathrm{MR}=1.65, \mathrm{Pc}=690 \mathrm{kPa}$} \\
\hline GO2/Ethanol & 53.7 & 54.8 & 16.0 & 282 & -- \\
\hline $\mathrm{MR}=2.08, \mathrm{Pc}=690 \mathrm{kPa}$ & & & & & \\
\hline $\begin{array}{l}\text { Liquid Gun Propellant, LP XM-46 } \\
\mathrm{Pc}=690 \mathrm{kPa}\end{array}$ & 7.72 & 8.27 & 0.43 & 465 & 1.70 \\
\hline
\end{tabular}




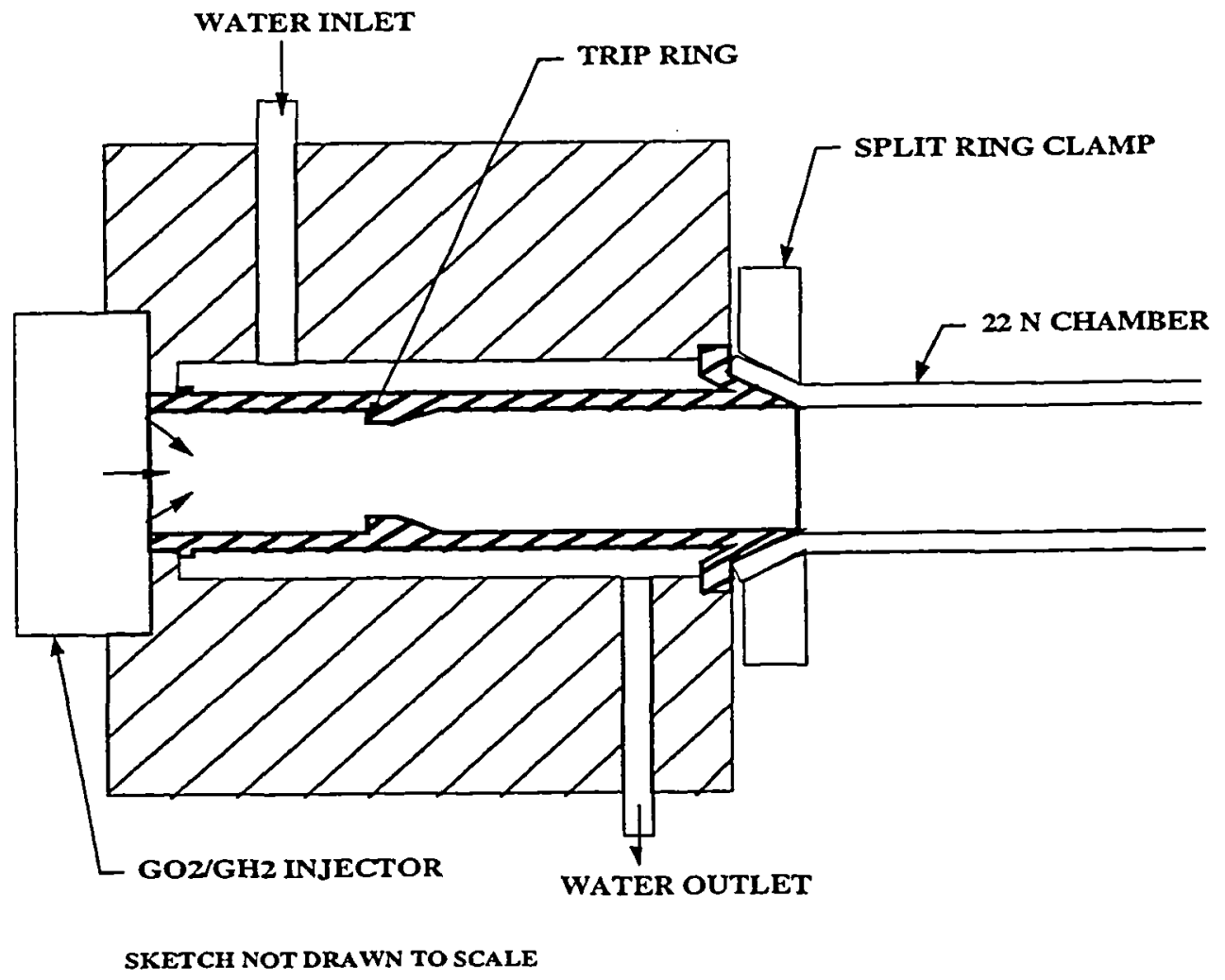

Figure 1: Injector Assembly for Testing $22 \mathrm{~N}$ Rocket Chambers 


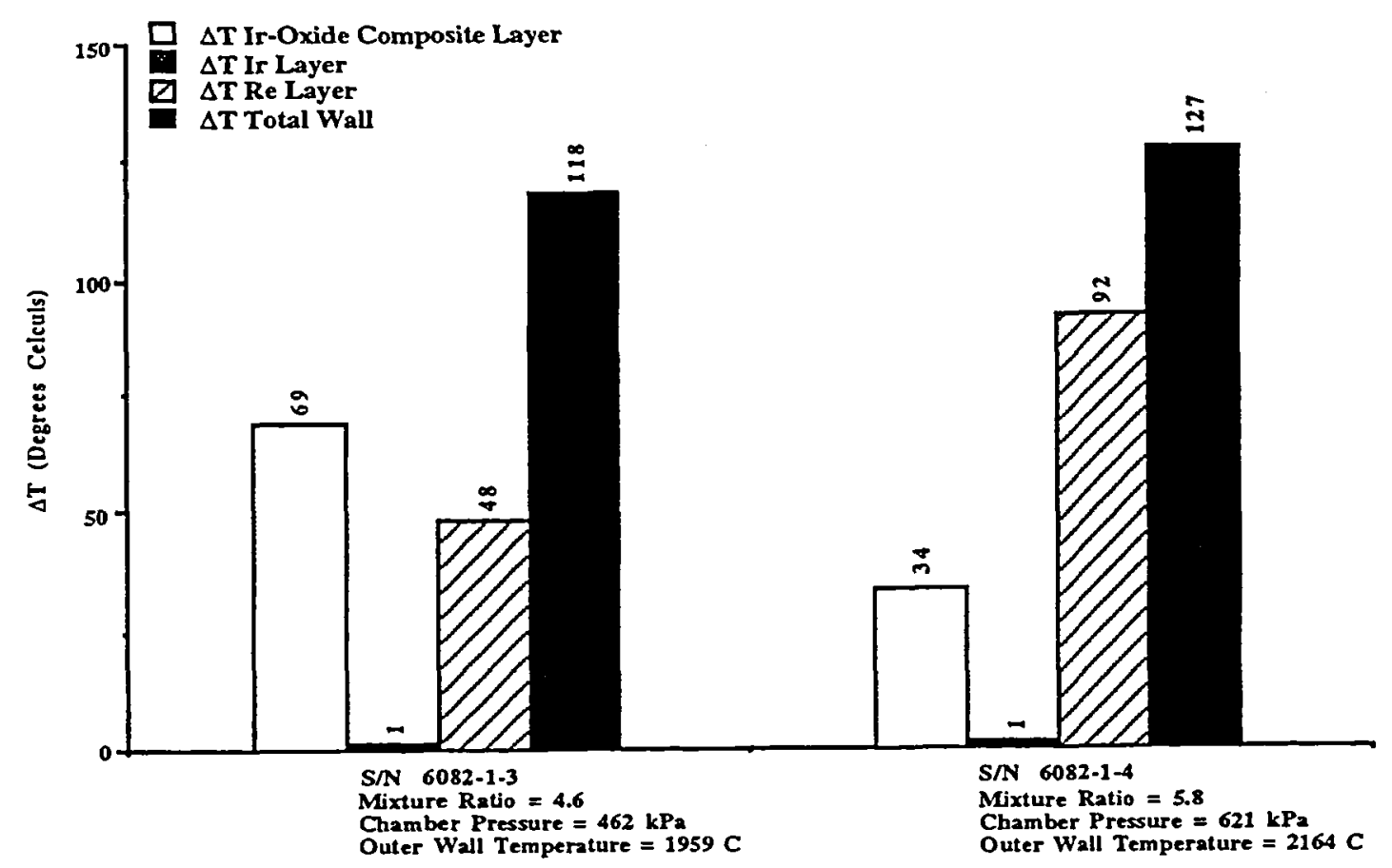

Figure 2: Wall Temperature Gradients for the S/N 6082 Chambers

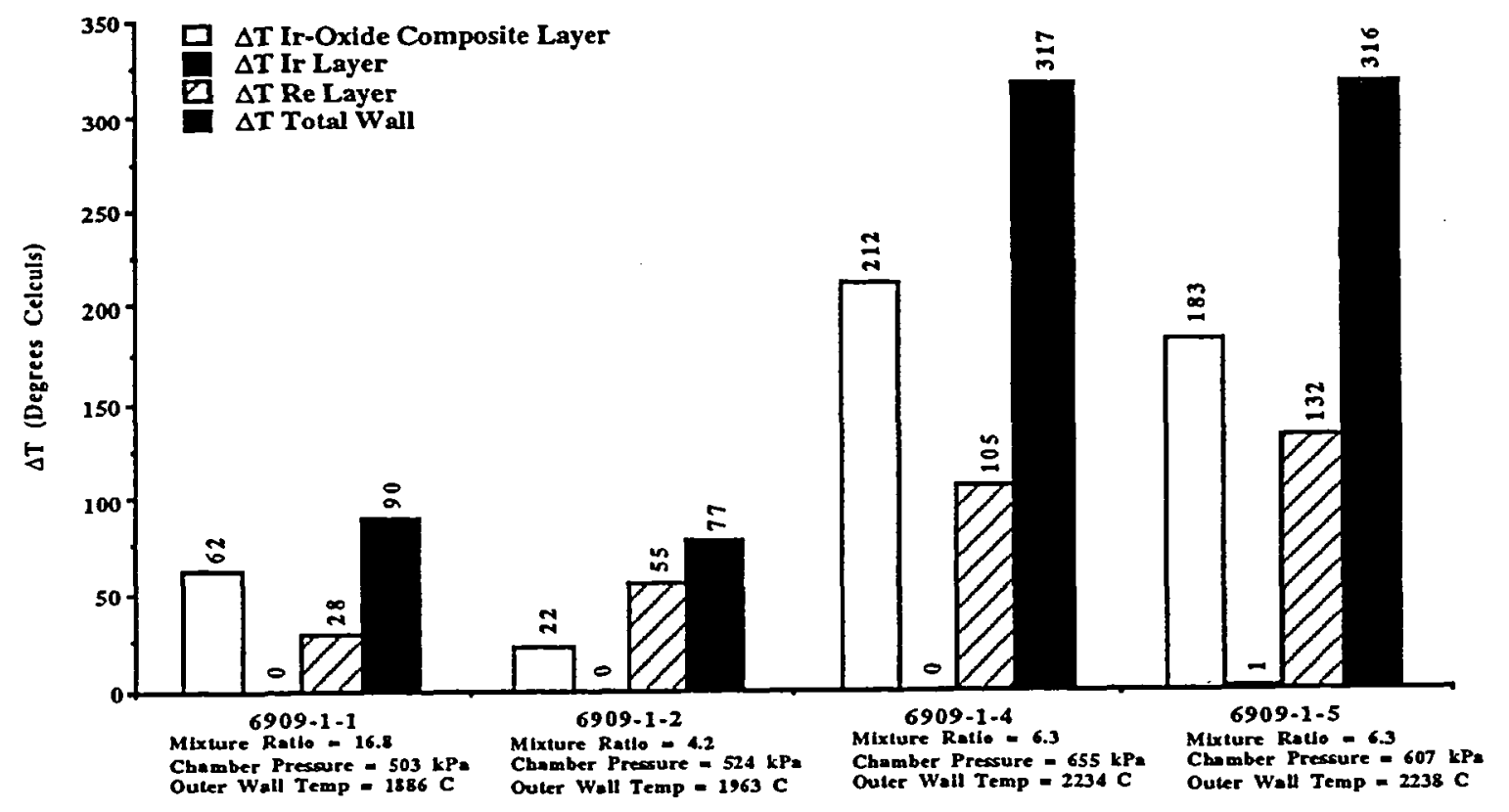

Figure 3: Wall Temperature Gradients for the S/N 6909 Chambers 


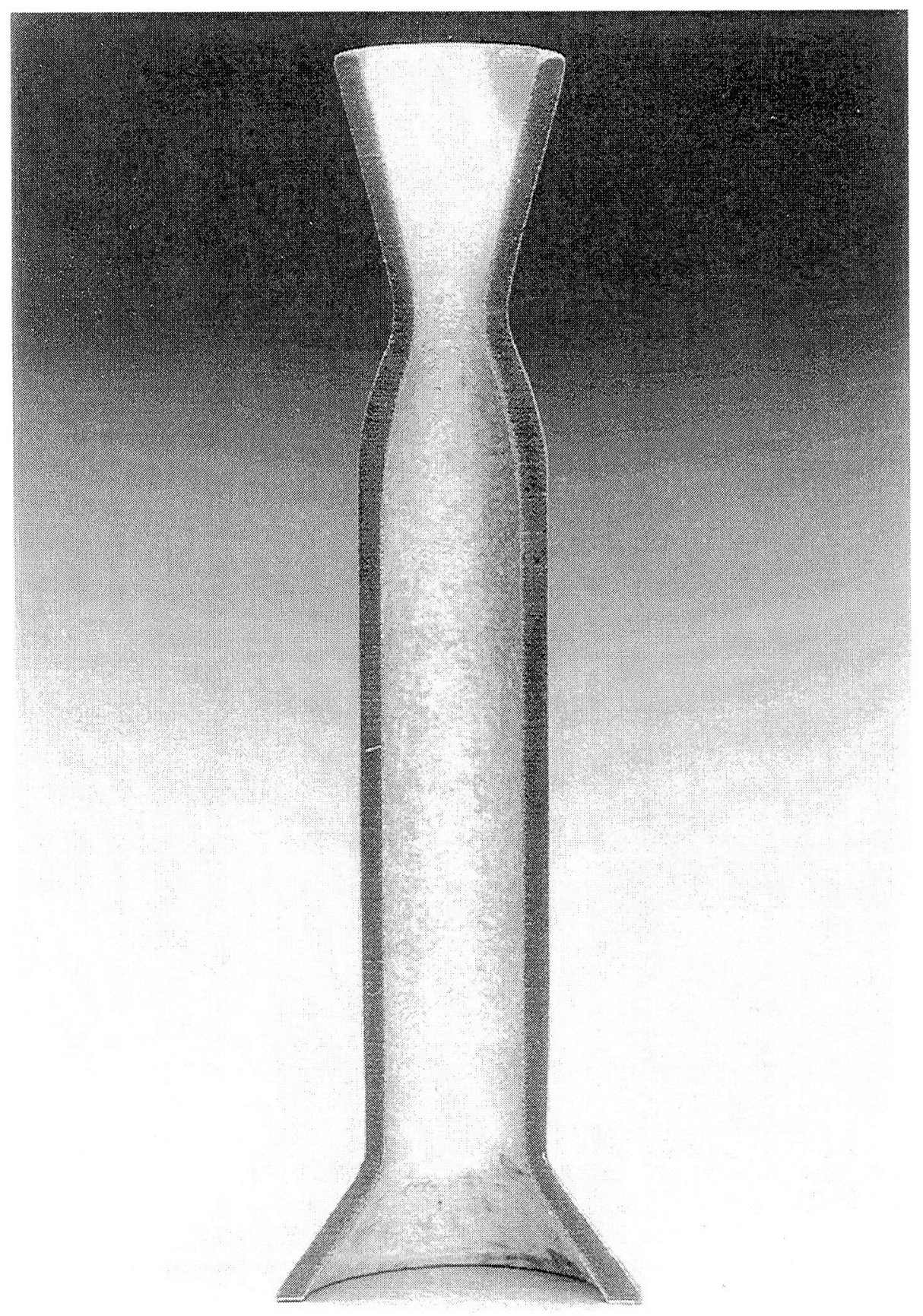

Figure 4: Sectioned S/N 6082-1-3 Chamber 


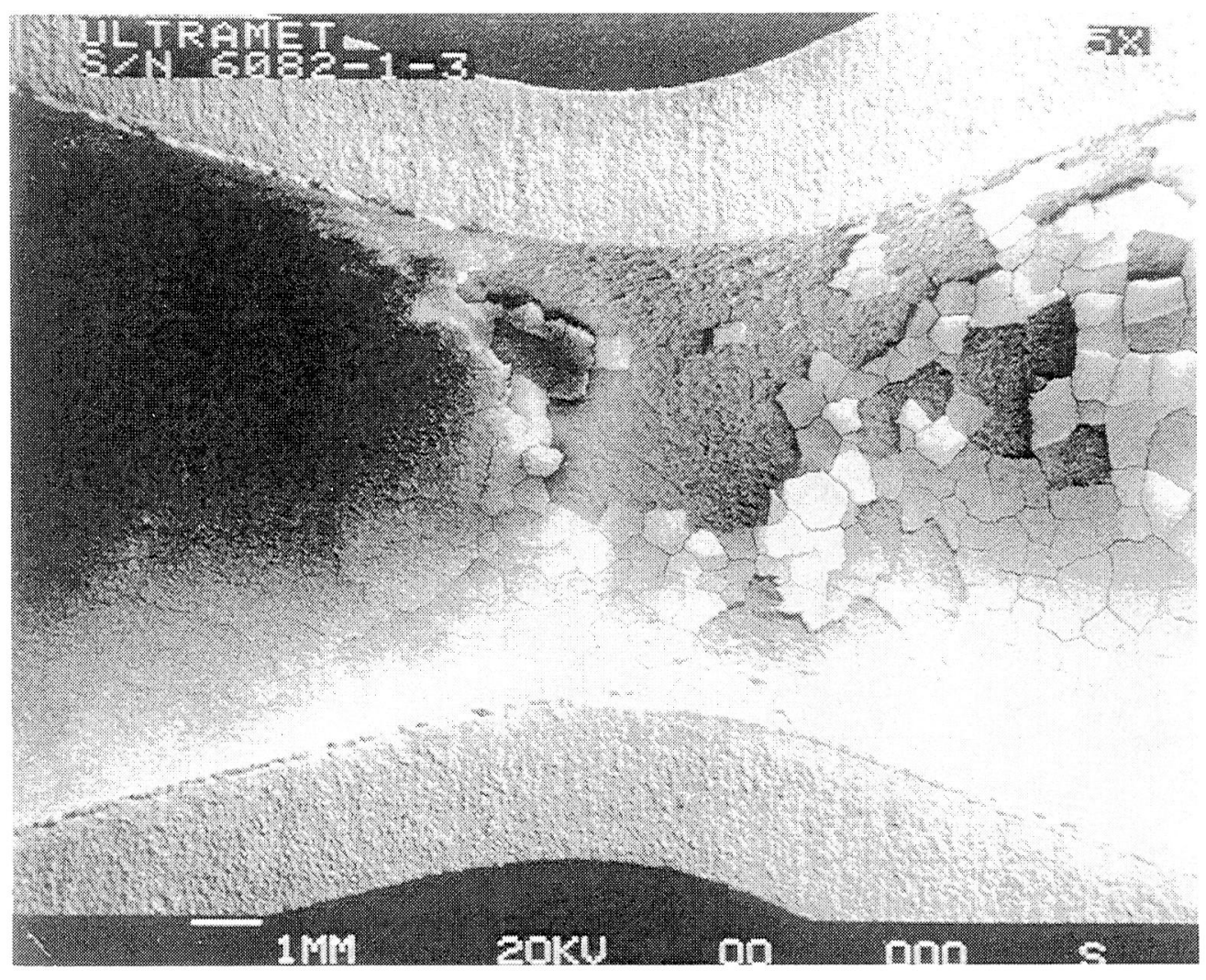

Figure 5: Micrograph of Sectioned S/N 6082-1-3 Chamber (Throat Region)

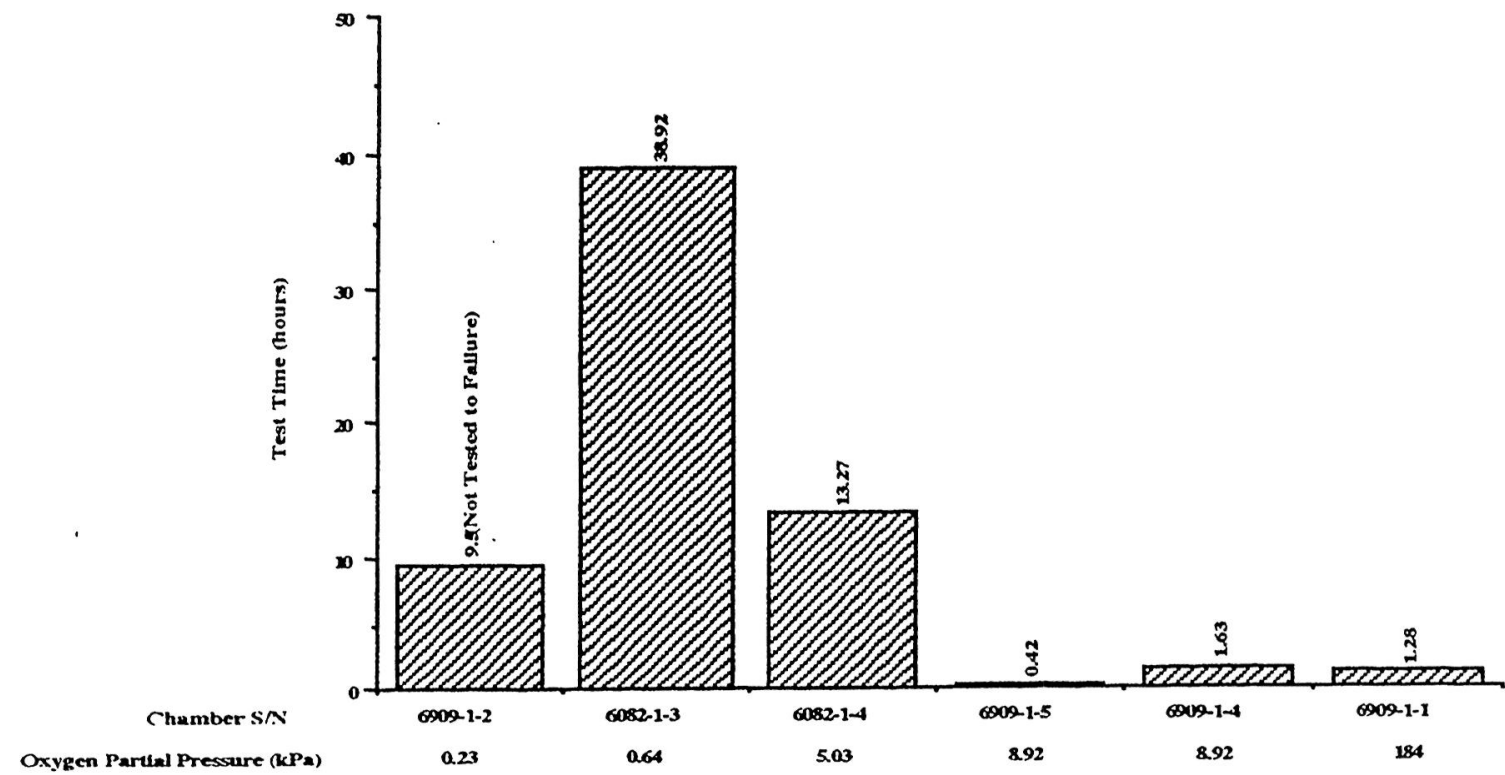

Figure 6: Test Time in Oxygen Environment 
Public reporting burden for this collection of intormation is estimated to average 1 hour per response, including the time for teviewing instructions, searching existing data sources. gathering and maintaining the data needed, and completing and reviewing the collection of information. Send comments regarding this burden estimate or any other aspect of this colloction of information including suggestions for reducing this burden, to Washington Headouarters Services, Directorate for Intormation Operations and Reports, 1215 Jefferson Davis Highway, Suite 1204, Arlington, VA 22202-4302, and to the OHtice of Management and Budget, Paperwork Reduction Project (0704-0188), Washington, DC 20503.

\begin{tabular}{|l|l|l|l}
\hline 1. AGENCY USE ONLY (Leave blank) & $\begin{array}{r}\text { 2. AEPORT DATE } \\
\text { September } 1995\end{array}$ & $\begin{array}{r}\text { 3. REPORT TYPE AND DATES COVERED } \\
\text { Technical Memorandum }\end{array}$ \\
\hline
\end{tabular}

4. TITLE AND SUBTITLE

5. FUNDING NUMBERS

Long Life Testing of Oxide-Coated Iridium/Rhenium Rockets

WU-232-02-03

6. AUTHOR(S)

Brian D. Reed

7. PERFORMING ORGANIZATION NAME(S) AND ADDRESS(ES)

8. PERFORMING ORGANIZATION REPORT NUMBER

National Aeronautics and Space Administration

Lewis Research Center

Cleveland, Ohio 44135-3191

E-9902

9. SPONSORING/MONITORING AGENCY NAME(S) AND ADDRESS(ES)

10. SPONSORING/MONTIORING AGENCY REPORT NUMBER

National Aeronautics and Space Administration

Washington, D.C. 20546-0001

NASA TM-107054

11. SUPPLEMENTARY NOTES

Prepared for the 31st Joint Propulsion Conference and Exhibit cosponsored by AIAA, ASME, SAE, and ASEE, San Diego, Califomia, July 10-12, 1995. Responsible person, Brian D. Reed, organization code 5330, (216) 977-7489.

12a. DISTRIBUTIONAVAILABILITY STATEMENT

12b. DISTRIBUTION CODE

Unclassified -Unlimited

Subject Category 20

This publication is available from the NASA Center for Aerospace Information, (301) 621-0390.

13. ABSTRACT (Maximum 200 words)

22-N class rockets, composed of a rhenium (Re) substrate, an iridium (Ir) coating, and an additional composite coating consisting of Ir and a ceramic oxide, were tested on gaseous oxygen/gaseous hydrogen (GO2/GH2) propellants. Two rockets were tested, one for nearly 39 hours at a nominal mixture ratio (MR) of 4.6 and chamber pressure (Pc) of $469 \mathrm{kPa}$, and the other for over 13 hours at a nominal MR of 5.8 and $621 \mathrm{kPa} \mathrm{Pc}$. Four additional Ir/Re rockets, with a composite Ir-oxide coating fabricated using a modified process, were also tested, including one for 1.3 hours at a nominal MR of 16.7 and $\mathrm{Pc}$ of $503 \mathrm{kPa}$. The long lifetimes demonstrated on low MR GO2/GH2 suggest greatly extended chamber lifetimes (tens of hours) in the relatively low oxidizing combustion environments of Earth storable propellants. The oxide coatings could also serve as a protective coating in the near injector region, where a still-mixing flowfield may cause degradation of the Ir layer. Operation at MR close to 17 suggests that oxide-coated Ir/ Re rockets could be used in severely oxidizing combustion environments, such as high $\mathrm{MR} \mathrm{GO2/GH2,} \mathrm{oxygen/hydrocarbon,} \mathrm{and} \mathrm{liquid} \mathrm{gun} \mathrm{propellants.}$

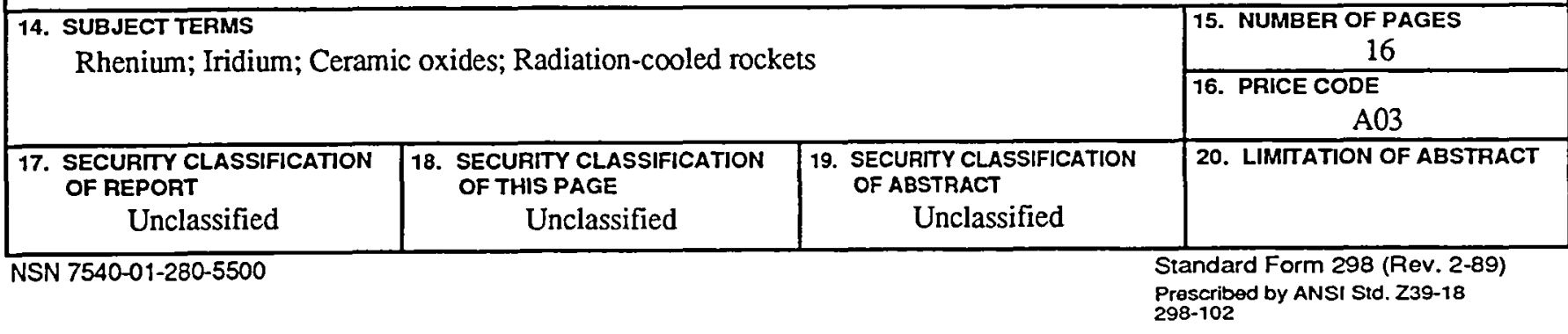

